\title{
Perception of Attitude to Fast-Food Restaurants: A Comparative Study of Male and Female Consumers
}

\author{
Aliaa Mokhtar Gaber Elnagar \\ Mohammed Abdel Wahab Morsy
}

Mohammed Sheded Hassan Gad Al rab

\begin{abstract}
Fast-food restaurants are preferred by both male and female consumers for different reasons. Therefore this research aims to compare the perceptions and attitudes of males and females about fast-food restaurants in greater Cairo.

A self-administered survey questionnaire was used to collect data; 300 participants of $11 \mathrm{yrs}$ old or above (150 females and 150 males) were asked to complete the questionnaires.

The findings revealed that males regard the superiority of the menu as follows: menu variety, innovative food, fresh ingredients, appropriate temperature, pleasing appearance and flavor of meals but the size of portion is of no importance. On the other hand females considered that size of portion and freshness of food ingredients as good; menu variety, meals flavor and pleasing appearance as average; innovative food as poor, and appropriateness of the temperature as very poor. The study gives relevant recommends.
\end{abstract}

Key words: Gender, fast-food, perception, attitude.

\section{INTRODUCTION}

People life is changing dramatically, time is running out and they want to achieve more in less time (de Rezende\& de Avelar, 2011). This rapid life caused a dramatic increase in consuming food away from home especially in fast food outlets which is responsible for $72.8 \%$ of whole food industry revenue (Periraet al., 2005). Eating out also has become a fashion as customers are not only eating, but also enjoying the environment and celebrating special occasions (Warde and Martens 2000). In a similar context, Freeman (2011) found that $78 \%$ of adults agreed that going out to a restaurant allowed them an opportunity to socialize, and $40 \%$ felt that visiting restaurants makes them more productive in their day-to-day lives.Customers may eat out for convenience, enjoyment, cheaper price and speedy service.

There are external and internal factors affecting customer perceptions and attitudes towards fast food restaurants. These factors include culture and social class, family or group, environment (Bhuyan`s, 2011; Mikkelsen, 2011), attractive décor and atmosphere (Alonso and O`neill, 2010), comfort and quality(Sulek and Hensley,2004), taste of food (Soriano, 2003), quality of service(Bhuyan,2011), persons' life style, brand image (Fischer et al., 2010), quality of staff (Roberts et al, 2010), price(Reyes, 2011), menu variety, gender (Beardsworth et al., 2002), Age (Siudzinski,2001), parking spaces(Bojanic,2007), cleanliness(Henson et al., 2006).

Although the subject of fast food operations gained high consideration of both academics and professionals, it seems that the effect of gender on the perception and attitude gained limited attention particularly true in Egypt .Therefore this research paper aimed to study the influence of gender on the customer's perception and attitudes of fast food operations in greater Cairo.

\section{MATERIALS AND METHODS}

The sample of this study consisted of 300 customers at fast food restaurant aged $\geq 11$ yrs old (150 males and 150 females). The participants were recruited from fast food operations namely of international chain restaurants -KFC and MacDonald- and national chain restaurant MO 'men in Greater Cairo.

The study used four- group administered questionnaire that covers demographic data, reasons of eating out, perception and attitude of eating out and opinions suggestions and of the participants. The questionnaire also included a group of questions concerning fast food restaurant visiting frequency and preferences.

The data were analyzed by using the SPSS (version 16) 


\section{RESULTS AND DISCUSSION}

Table (1) Demography analysis

\begin{tabular}{|l|l|c|}
\hline \multicolumn{2}{|l|}{ Factors } & Percentages \\
\hline \multirow{5}{*}{ Gender } & Males & $50 \%$ \\
\cline { 2 - 3 } & Females & $50 \%$ \\
\hline \multirow{5}{*}{ Age } & $11-18$ years old & $29 \%$ \\
\cline { 2 - 3 } & $19-40$ years old & $64 \%$ \\
\cline { 2 - 3 } & 40 and more & $15 \%$ \\
\hline \multirow{5}{*}{ Education level } & Primary & $9 \%$ \\
\cline { 2 - 3 } & Secondary & $17 \%$ \\
\cline { 2 - 3 } & Occupational & $8 \%$ \\
\cline { 2 - 3 } & University graduate & $4 \%$ \\
\cline { 2 - 3 } & Post graduate & \multirow{2}{*}{$8 \%$} \\
\hline
\end{tabular}

The study sample of the current research includes $50 \%$ female and 50\% male. The higher number of the female reflects the fact that women in Egypt have become a remarkable portion of the workforce and have limited time to cook at home. This result agreed with Atkins and Bouler (2001) and French et al (2001) in that great changes have occurred in our society. Women being a part of Egyptian work force have no time to cook, smaller size of family and population growth. This in turn led to the change in teenage culture and what they have been raised on in terms of eating habits

The Education level considerably influenced the perception and attitude of eating out home, In this context, the results of the current study (Table 1) show that $59 \%$ of the fast food customers were university graduates. Similar results were reported by Allen et al (2007).

Table (2) with whom you go to eat out.

\begin{tabular}{|l|c|c|c|c|}
\hline \multicolumn{1}{|c|}{ Gender } & Alone & With friends & With family & $\begin{array}{c}\text { With your } \\
\text { Children }\end{array}$ \\
\hline Male & $2.9 \%$ & $19.3 \%$ & $18 \%$ & $3.5 \%$ \\
\hline Female & $3.2 \%$ & $20.6 \%$ & $24.12 \%$ & $7.1 \%$ \\
\hline
\end{tabular}

It is clear from Table (2) that $19.3 \%$ of females prefer to eat with friends and $2.9 \%$ always desire to eat alone. Regarding males, $24.12 \%$ eat with their families, but only $3.2 \%$ prefer to eat alone. It could be concluded that males and females vary in their preferences. 
Table (3) Service type

\begin{tabular}{|l|c|c|c|}
\hline Gender & at restaurant & Take away & Both \\
\hline Male & $20.9 \%$ & $3.5 \%$ & $16.7 \%$ \\
\hline Female & $20.8 \%$ & $7.72 \%$ & $23.9 \%$ \\
\hline
\end{tabular}

Regarding seating versus "take away", $20.9 \%$ of female prefer eating at the resturant and $3.5 \%$ prefer "take away"; $23.9 \%$ of males prefer dining room as eating place and the same percentage like "take away" eating style, and $7.72 \%$ like take away only (table 3 ).

Table (4) Favorite meal

\begin{tabular}{|l|c|l|l|}
\hline Gender & \multicolumn{1}{|l|}{ Breakfast } & \multicolumn{1}{l|}{ Lunch } & \multicolumn{1}{l|}{ Dinner } \\
\hline Male & $2.6 \%$ & $21.5 \%$ & $19.6 \%$ \\
\hline Female & $5.18 \%$ & $25.4 \%$ & $24.8 \%$ \\
\hline
\end{tabular}

Table (4) indicates no differences between males and females regarding favorite meal as both of them prefer lunch meal in fast food restaurants.

Table (5) Visiting frequency

\begin{tabular}{|l|c|l|l|}
\hline Gender & Once a week & $\begin{array}{l}\text { Twice } \\
\text { a week }\end{array}$ & More \\
\hline Male & $26.4 \%$ & $9.03 \%$ & $8.6 \%$ \\
\hline Female & $28.9 \%$ & $16.1 \%$ & $10.9 \%$ \\
\hline
\end{tabular}

Regarding the frequency of weekly visits, no remarkable differences were found between both males (26.4\%) and females $(28.9 \%)$ (Table5). 
Table (6) Reasons of eating out ranked in a descending order

\begin{tabular}{|l|l|}
\hline \multicolumn{1}{|c|}{ Males } & \multicolumn{1}{c|}{ Females } \\
\hline 1-travelling. & 1-close to your home. \\
\hline 2-it is fast and ready. & 2-price. \\
\hline 3-like the taste of food. & 3-no time to cook. \\
\hline 4-famous. & 4-it is fast and ready. \\
\hline 5-energetic atmosphere. & 5-like the taste of food. \\
\hline 6-no time to cook. & 6-It is close to shopping areas. \\
\hline 7-price. & 7-it is a habit. \\
\hline 8-it is close to shopping areas. & 8-famous. \\
\hline 9-close to your home. & 9-entertainment. \\
\hline 10-entertainment. & 10-Travelling. \\
\hline 11-it is a habit. & 11-energetic atmosphere. \\
\hline
\end{tabular}

While males perceive travelling as their main or the $1^{\text {st }}$ reason for eating out, it is number 10 for females; closeness to home is the principle reason for eating out by female. Eating out as a habit is number, 11 for males and number 7 for female. Price is considered the $2^{\text {nd }}$ reason by females and the $7^{\text {th }}$ by males. It is clear from the results presented in table (6) that there is no any similarity between males and females in the first five reasons of eating out. Energetic atmosphere of the dining out is relatively preferable by males since it appeared in the $5^{\text {th }}$ rank, but at the bottom of the list for females.

Table (7) Factors affecting the food quality in order.

\begin{tabular}{|l|r|}
\hline \multicolumn{1}{|c|}{ Males } & \multicolumn{1}{|c|}{ females } \\
\hline 1. Freshness. & 1. Size of portion. \\
\hline 2. Appropriate temperature. & 2. Fresh ingredients. \\
\hline 3. Menu variety. & 3. Pleasing appearance. \\
\hline 4. Innovative food. & 4. Menu variety. \\
\hline 5. Pleasing appearance. & 5. Flavor of food. \\
\hline 6. Flavor of food. & 6. Innovative food. \\
\hline 7. Size of portion. & 7. Appropriate temperature. \\
\hline
\end{tabular}

Table (7) shows that the Size of the meal portion is considered as the first priority by females, but it is listed at the bottom of priorities by males. On the other hand freshness, menu variety and flavor of food ranked closely but not identical for males and females. 
Table (8) Factors affecting the quality of service

\begin{tabular}{|l|l|}
\hline \multicolumn{1}{|c|}{ Males } & \multicolumn{1}{c|}{ Females } \\
\hline 1. Employees' appearance. & 1. Courtesy of employees. \\
\hline 2. Equipment. & 2. Open 24 hours. \\
\hline 3. Open 24 hours. & 3. Equipment. \\
\hline 4. Courtesy of employees. & 4. Employee appearance. \\
\hline 5. Speed of service. & 5. Speed of service. \\
\hline
\end{tabular}

The results of Table (8) clearly indicate that the speed of service was identically perceived by males and females at the bottom of the list of the quality of service. Equipment and 24 hour opening occupy nearly the same category. Courtesy of employees was ranked first by females and fourth by males.

Regarding the menu price, it was seen reasonable by male but expensive by females. This is in accordance with the results reported by Zhu (2005), and Ozfer etal(2007). who mentioned that the quality/price ratio is a dominant factor for their experience.

The importance of different elements of fast food operation place is shown in table (9).

Table (9) Place

\begin{tabular}{|l|l|}
\hline \multicolumn{1}{|c|}{ Males } & \multicolumn{1}{|c|}{ Females } \\
\hline 1. Location. & 1. Location. \\
\hline $\begin{array}{l}\text { 2. Attractiveness of dining room } \\
\text { decoration }\end{array}$ & \begin{tabular}{l} 
2. Cleanliness. \\
\hline 3. Parking service.
\end{tabular} \\
\hline 4. Cleanliness. & $\begin{array}{l}\text { attractiveness of dining room } \\
\text { decoration }\end{array}$ \\
\hline
\end{tabular}

Table (9) indicates that while location is ranked first by both males and females cleanliness came at the bottom of the list of males and parking spaces at the bottom of the females list.

The results of the current study indicated differences among customers perception and attitudes towards fast food restaurants according to gender, as the Standard Deviation and Standard Error of Mean values are = 0.01 for male and 0.03 for female and 0.01 for male and .01 for female respectively. This means that most participants responded differently to the questionnaire questions. Additionally, the results revealed that there is a significant difference between customers attitudes and perception according to gender (significance level for chi-Square $=0.000$ ). 


\section{Recommendations}

1. Restaurants have to emphasize on providing fresh ingredients for their customers. .

2. It is essential to handle customer complaints and respond instantly to their problems.

3. More attention should be given to the atmosphere and cleanness of the fast food outlets.

4. Fast food customers look for quicker service.

5. The temperature of food during its servicing should be improved to meet the customers' desire.

6. The authority of the fast food outlets must consider improving the appearance of the employees to motivate customers for repeating visits.

7. There is a need for clear and announced pricing policy for different items.

8. It is important to consider that fast food restaurants are dominated by females and their desire should be fulfilled.

9. Customers of fast food operations are highly educated, and this should be considered by managers in charge.

10. Fast food operations have to take into their consideration that their customers prefer eating in groups and for socializing purposes.

11. Lunch meals are the most preferable by fast food customers` and the operation must consider it their rush hours.

12. -Fast food restaurant managers should consider the size of portion as one of the limiting factors of repeating visit.

\section{References}

- Allen, K.N., Taylor, J.S. and Kuiper, R.A. (2007). "Effectiveness of nutrition education on fast food choices in adolescents". Journal of school nursing, vol. 23, no. 6, pp. 337-41.

- Alonso, A.D. And O’Neill. M.A. (2010). "Consumers' ideal eating out experience as it refers to restaurant style: A case study", Journal of Retail \& Leisure Property, Vol. 9 No. 4, pp. 263-276.

- Atkins, P. and Bouler,I. (2001), " food in society", economy, culture and geography , Arnold , London.

- Beardsworth, A., Brynan, A., Keil, T., Goode, J., Haslam, C. and Lancashire, E. (2002). "Women, men and food: the significance of gender for nutritional attitudes and choices". British Food Journal, Vol. 104 No. 7, pp. 470-91.

- Bhuyan, S. (2011). "Do consumers' attitudes and preferences determine their FAFH behavior? An application of the Theory of Planned Behavior", Agribusiness, Vol. 27 No. 2, pp. 205-220.

- Bojanic, D. (2007)."Customer profile of the carry out segment for restaurants "International journal of contemporary hospitality management vol.19, no. 1, pp.21-31.

- Clark, S. (2013)"fast food" updated 13 March 2013.

- De Rezende, D.C. and de Avelar, A.E.S. (2011). "Factors that influence the consumption of food outside the home in Brazil", International Journal of Consumer Studies, Vol. 36 No. 3, pp. 300-306.

- Fischer, M., Volckner, F.andSatter,H. (2010), "how important are brands ? Across-category, crosscountry study", journal of marketing research, vol. 47, no. 5, pp.823 -9.

- Freeman, E., Mc Connell. (2011)."Restaurant industry sustainability; Barriers and solutions to sustainable practice indicators ".master of science. Arizona state university .p.4.

- French S.A., Story M, Jeffery, R.W (2001), "environmental influences on eating and physical activity. Annual review of public health, vol. 22, no. 30, pp.9-35.

- Henson, S., Majowicz, S., Masakure, O., Sockett, P., Jones, A., Hart, R., Carr, D. And Knowles, L. (2006). "Consumer assessment of the safety of restaurants: The role of inspection notices and other information cues", Journal of Food Safety, Vol. 26, pp. 275-301. 
- Mikkelsen, B.E. (2011). "Images of foodscapes: Introduction to foodscapes studies and their application in the study healthy eating out-of-home environments". Perspectives in Public Health, Vol. 131 No. 5, pp. 209-216.

- Ozfer, A.; Celik, O.;Akan, 1.Sariye; S.,metin. S. (2007). "An evaluation of fast food preferences according to gender". Humanity and social sciences journal. 2(1): 43- 50.

- Pereira mark, A. and Kartashoy, alex and Ebbeling, Cara, B.(2005), "fast food habits, weight gain, and insulin resistance ( the CARDIA study):15 years prospective analysis", the lancet, vol. 365,no. 9453,pp. 36-42.

- Reyes, U.S. (2011)." Fast food industry: keeping up with the changing life style." Agriculture and agri- food .Canada .Agri food trade service .p.3.

- $\quad$ Robert, Linda; Deery, Margaret; Hede,Anne, Marie (2010)." The vision for food service" .p. 5, 8.

- Siudzinski,p. (2001), " recruiting tool", restaurant business, vol. 100, no, 5, pp. 17.

- Soriano, D. (2003). "Customers' expectations factors in restaurants: The situation in Spain". The International Journal of Quality and Reliability, Vol. 19 No. 8/9, pp. 1055-1068.

- Sulek, J.M. and Hensley, R.L. (2004). "The relative importance of food, atmosphere, and fairness of wait: the case of a full-service restaurant". Cornell Hotel \& Restaurant Administration Quarterly, Vol. 45 No. 3, pp. 235-247.

- Warde, A., Cheng, S.L., Olsen, W. and Southerton, D. (2007). "Changes in the practice of eating: a comparative analysis of time-use", ActaSociologica, Vol. 50 No. 4, pp. 363-385.

- Zhu, h.(2005)." Fast food in a Chinese provincial city: A comparative analysis". Texas University. p. 62. 
الملخص العربي

انتشرت فى العقود الثنالثة الأخيرة مطاعم الوجبات السريعة فى دول العالم النامى والمتقدم على حد سواء، وأصبحت تنتشر فى جميع ربوع

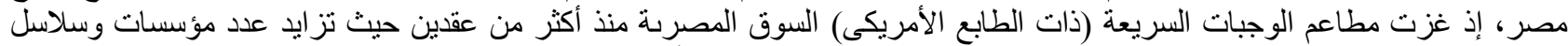

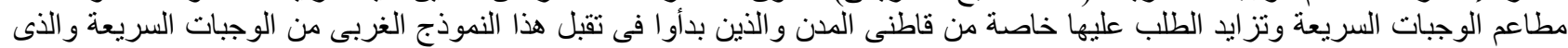

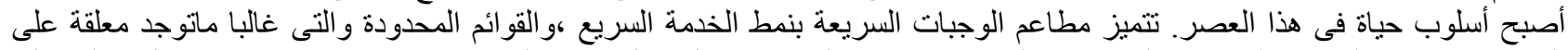

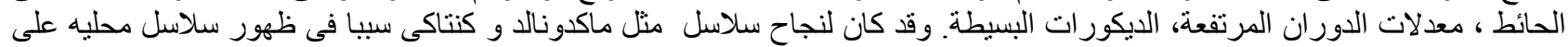

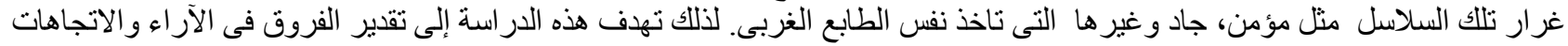

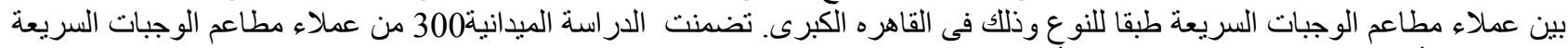

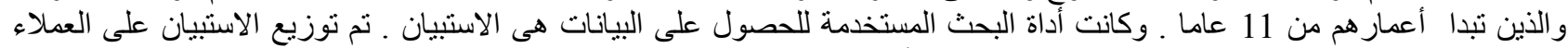

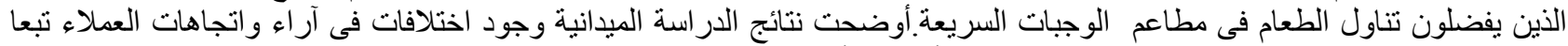

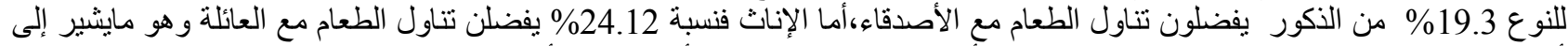

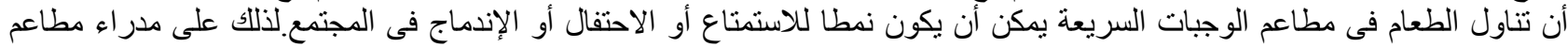

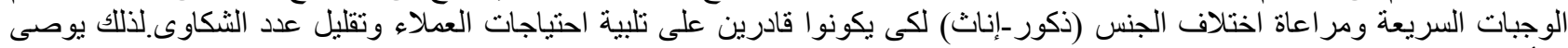

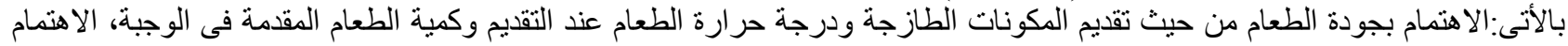

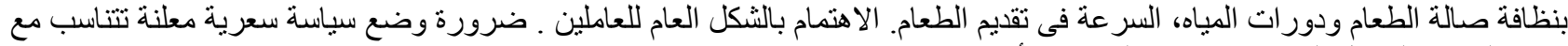
جميع الفئات؛ التعامل السريع مع جميع الثكاوى بأقصى سر عة ممكنة. 